\section{TOOTHPASTE WITH EXTENSIVE BENEFITS}

Newly launched Oral-B Pro-

Expert toothpaste provides

its extensive health benefits

with the joint heritage of two-

company backing (Procter

\& Gamble and Oral-B) with

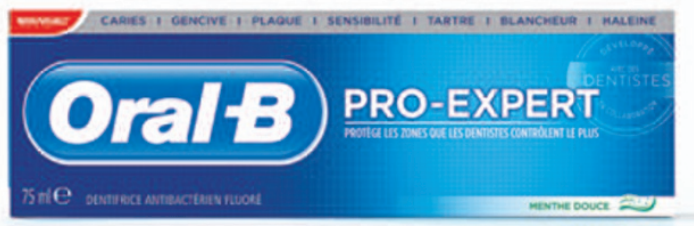

decades of steady research and

clinical development.

The all-in-one Oral-B Pro-Expert toothpaste derives its benefits against gum problems, plaque, caries, calculus formation, dentinal hypersensitivity, staining and bad breath from the evolution of its two main active ingredients: stabilised stannous fluoride and polyphosphate.

Stannous fluoride was introduced by $\mathrm{P} \& \mathrm{G}$ with Crest, the first clinically proven fluoride toothpaste in 1955. Although widely recognised for its anti-caries properties, stannous fluoride is relatively unstable in water-solution. However, the evolution of an innovative formulation with polyphosphate has enabled an effective combination.

Stannous fluoride is an effective antimicrobial, delivering plaque control and anticaries benefits as well as dentinal hypersensitivity relief, while polyphosphate protects against calculus formation, staining and bad breath.

Reader response number 50

\section{CONGRESS WILL APPEAL TO ALL}

This year's Association of Dental Implantology UK (ADI) Team Congress will take place on 14-15 April at Manchester Central Convention Complex.

ADI President Stephen Jacobs, along with Michael

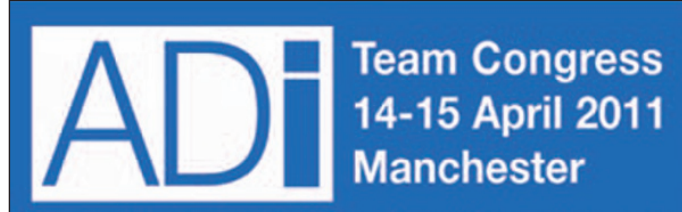

what we know, what we think we know and what we think we don't know about implant dentistry
Norton, the ADI's Scientific Chairman, have put together a two-day programme that should appeal to all members of the dental implant team. Stephen believes that 'the congress has now become the leading dental implant meeting in the UK and one of the foremost in Europe, with the unique combination of a plenary programme with internationally renowned speakers, parallel sessions for all dental care professionals, a large technical exhibition and a fantastic party.' Speakers include: Tara Aghaloo (USA), Tomas Albrektsson (Sweden), Mauricio Araujo (Brazil), Oliver Brix (Germany), Torsten Jemt (Sweden), Joseph Kan (USA), Michel Magne (USA), Clark Stanford (USA), Stephen Wallace (USA), Stephen Wheeler (USA) \& Anita Daniels (USA). To book visit the ADI website at www.adi.org.uk/congress 2011.

Reader response number 52

\section{TALKING POINTS REGISTRATION OPENS}

Registration is now open for this year's Talking Points in Dentistry lecture series, developed by GSK and held at nine venues across the UK during May.

Nicola West and Roger Yates' presentation is titled 'Where's the Smile Line? Planning in Periodontal Management', and will provide an overview of current periodontal treatment regimens, with particular emphasis on the aesthetic outcome of treatment.

Mhari Coxon's lecture observes that 'The Wise Man Builds His Practice on Prevention, and will focus on the role of the team in promoting patient satisfaction and reducing the risk of litigation following a missed diagnosis of periodontal disease.

Dental professionals interested in attending their local event should visit www.gskdentalprofessionals.co.uk.

Reader response number 53

\section{HELPYOUR PHOBIC PATIENTS}

Aztec Health is dedicated to providing timeefficient dental CPD training based around the use of simple hypnotherapy techniques in conjunction with a $\mathrm{CD}$ that patients can use prior to visiting the dentist, in the waiting room or even during their treatment.

Aztec Health are holding one-day CPD training sessions for dental professionals across the UK, starting in Birmingham on 18 March. Delegates will leave with a useful new skills set to use in their practice, including the opportunity to retail the Dreamweaver Relaxation Specific CD to patients.

The training module costs $£ 175$ including refreshments, lunch and a training manual. Each delegate will also be supplied with $15 \mathrm{CDs}$ worth $£ 149$, providing an immediate return on their financial investment.

The training meets GDC criteria for verifiable $\mathrm{CPD}$ and delegates will be issued with a certificate on completion of the module. Reader response number 51

\section{A BRUSH FOR PATIENTS IN A RUSH}

The Cavex Rush Brush is a ready to use toothbrush impregnated with toothpaste. It is aimed at the patient who has not had time to clean their teeth before visiting the surgery or as an inexpensive way to demonstrate cleaning and brushing technique.

Each Rush Brush is individually packaged for convenience and the small head size allows excellent access to all areas of the mouth. Although inexpensive the Rush Brush has a fresh mint taste and soft quality bristles which are kind to gums. A box of 100 brushes costs $£ 15+$ VAT (RRP).

Reader response number 54

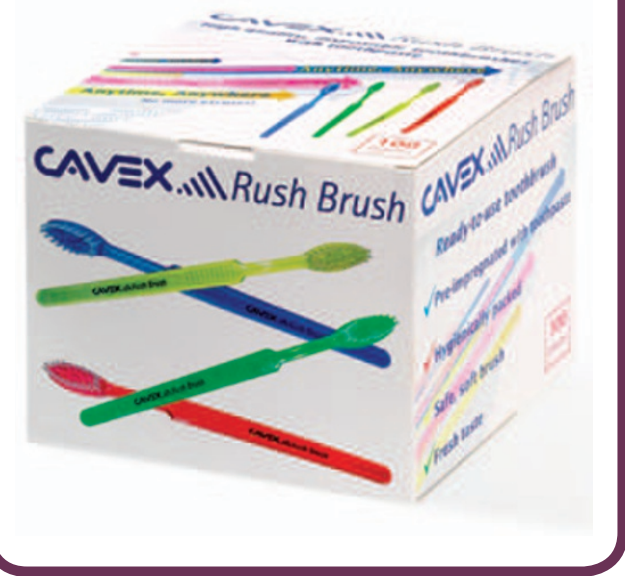

